\title{
Neuropeptide Y-mediated sex- and afferent-specific neurotransmissions contribute to sexual dimorphism of baroreflex afferent function
}

\author{
Yang Liu ${ }^{1, *}$, Di Wu ${ }^{2, *}$, Mei-Yu Qu ${ }^{2, *}$, Jian-Li He ${ }^{2}$, Mei Yuan1, Miao Zhao ${ }^{2}$, Jian-Xin Wang ${ }^{2}$, \\ Jian $\mathrm{He}^{2}$, Lu-Qi Wang ${ }^{2}$, Xin-Jing Guo ${ }^{1}$, Meng Zuo ${ }^{1}$, Shu-Yang Zhao ${ }^{2}$, Mei-Na Ma², \\ Jun-Nan Li ${ }^{1}$, Weinian Shou ${ }^{3}$, Guo-Fen Qiao', ${ }^{1,2}$, Bai-Yan Li ${ }^{1}$ \\ ${ }^{1}$ Department of Pharmacology, Harbin Medical University, Harbin, China \\ ${ }^{2}$ Key Laboratory of Cardiovascular Research of Ministry of Education, Harbin Medical University, Harbin, China \\ ${ }^{3}$ Riley Heart Research Center, Division of Pediatric Cardiology, Herman B. Wells Center for Pediatric Research, Department of \\ Pediatrics, Indiana University School of Medicine, Indianapolis, IN, USA \\ *These authors have contributed equally to this work \\ Correspondence to: Bai-Yan Li, email: liby@ems.hrbmu.edu.cn \\ Guo-Fen Qiao, email: qiaogf88@163.com \\ Keywords: neuropeptide Y, baroreflex, nodose ganglion, nucleus tractus solitarii, whole-cell patch techniques \\ Received: October 27, $2015 \quad$ Accepted: July 16, $2016 \quad$ Published: September 07, 2016
}

\section{ABSTRACT}

Background: Molecular and cellular mechanisms of neuropeptide-Y (NPY)mediated gender-difference in blood pressure (BP) regulation are largely unknown.

Methods: Baroreceptor sensitivity (BRS) was evaluated by measuring the response of BP to phenylephrine/nitroprusside. Serum NPY concentration was determined using ELISA. The mRNA and protein expression of NPY receptors were assessed in tissue and single-cell by RT-PCR, immunoblot, and immunohistochemistry. NPY was injected into the nodose while arterial pressure was monitored. Electrophysiological recordings were performed on nodose neurons from rats by patch-clamp technique.

Results: The BRS was higher in female than male and ovariectomized rats, while serum NPY concentration was similar among groups. The sex-difference was detected in $Y_{1} R$, not $Y_{2} R$ protein expression, however, both were upregulated upon ovariectomy and canceled by estrogen replacement. Immunostaining confirmed $Y_{1} R$ and $Y_{2} R$ expression in myelinated and unmyelinated afferents. Single-cell $P C R$ demonstrated that $Y_{1} R$ expression/distribution was identical between $A$ - and C-types, whereas, expressed level of $Y_{2} R$ was $\sim 15$ and 7 folds higher in Ah- and C-types than A-types despite similar distribution. Activation of $Y_{1} R$ in nodose elevated $B P$, while activation of $Y_{2} R$ did the opposite. Activation of $Y_{1} R$ did not alter action potential duration (APD) of A-types, but activation of $Y_{2} R$ - and $Y_{1} R / Y_{2} R$ in Ah- and C-types frequency-dependently prolonged APD. $\mathrm{N}$-type $I_{\mathrm{Ca}}$ was reduced in A-, Ah- and C-types when either $Y_{1} R_{,} Y_{2} R$, or both were activated. The sex-difference in $Y_{1} R$ expression was also observed in NTS.

Conclusions: Sex- and afferent-specific expression of Neuropeptide-Y receptors in baroreflex afferent pathway may contribute to sexual-dimorphic neurocontrol of BP regulation.

\section{INTRODUCTION}

The pressor responses induced by neuropeptide $\mathrm{Y}$ (NPY) are greater in males compared with age-matched females [1] and the underlying molecular and cellular mechanisms are complex and largely unknown. Although no difference in serum concentration of NPY was found between genders, it could be elevated in both hypertensive men and women [2], suggesting at least that NPY itself would not be responsible for gender-related difference in blood pressure (BP) under physiological condition and the sex-differential expression of NPY receptors would be 
highly expected in either peripheral or central site of BP regulation. Early studies have demonstrated that activation of type-I NPY receptor ( $\mathrm{Y}_{1} \mathrm{R}$ ) leads to a vasodepressor response [3, 4], while type-II NPY receptor $\left(\mathrm{Y}_{2} \mathrm{R}\right)$ activation induces vasopressor action in nucleus tractus solitarii (NTS) $[4,5]$, indicating that $\mathrm{Y}_{1} \mathrm{R}$ and $\mathrm{Y}_{2} \mathrm{R}$ activations often mediate an opposite pressor response. Several lines of evidence also imply the central mechanisms of NPY in $\mathrm{BP}$ regulation and potentially differential role of its receptor activation at different level of baroreflex afferent pathway, such as nodose ganglion (NG) and NTS. Firstly, significant effects of gender on the central actions of NPY on vasopressin and BP have been reported [6]; secondly, $\mathrm{Y}_{2} \mathrm{R}$ mRNA expression is dramatically increased in the NTS at hypertensive condition, whereas it is decreased in the NG under the same experimental condition [7], suggesting that NPY and its receptors participate in the BP regulation under both physiological and hypertensive condition via modulating baroreflex afferent function. Recent results have indicated that naturally occurring genetic variation at the $\mathrm{Y}_{1} \mathrm{R}$ locus has implications for heritable autonomic control of the circulation and hypertension, suggesting novel pathophysiological links among the $\mathrm{Y}_{1} \mathrm{R}$ locus, autonomic activity, and $\mathrm{BP}$ [8]. $\mathrm{Y}_{2} \mathrm{R}$ expression is upregulated in spontaneously hypertensive rats [9] and endogenous expression of $\mathrm{Y}_{2} \mathrm{R}$ is also documented in neuroendocrine cells and neuroendocrine tissues including the brainstem of a rodent model of hypertension [10].

Collectively, all published records indicate that NPY plays a pivotal role in BP regulation and development of hypertension through either peripheral or central pathway with gender-specific manner. However, there is no published record showing the sex-specific expression and distribution of $\mathrm{Y}_{1} \mathrm{R}$ and $\mathrm{Y}_{2} \mathrm{R}$ in baroreflex afferent pathway including $\mathrm{NG}$ and NTS under normal or hypertensive condition. Moreover, a low-threshold and sex-specific distribution of myelinated Ah-type baroreceptor neurons (BRNs) housed in NG and NTS has been identified [11-14]. The neuroexcitability of this subpopulation depends upon the presence of estrogen $\left(17 \beta-E_{2}\right)[15-17]$ and is regulated by neurotransmitter [18], which may impact on the sexual dimorphism of baroreflex afferent function and neurocontrol of circulation [19]. Therefore, this study aims to explore sex- and afferentspecific expression and distribution of $Y_{1} R$ and $Y_{2} R$ in NG and NTS at tissue and single-cell level, the effect of direct injection of $\mathrm{Y}_{1} \mathrm{R}$ or $\mathrm{Y}_{2} \mathrm{R}$ agonist into $\mathrm{NG}$ on the mean arterial pressure (MAP), and the ion channel mechanism of neuroexcitation induced by $\mathrm{Y}_{1} \mathrm{R}$ and $\mathrm{Y}_{2} \mathrm{R}$ activation.

\section{RESULTS}

\section{Estrogen-dependent changes in baroreceptor sensitivity}

To explore whether the depressor reflex modulation of blood pressure is female hormone-dependent, the baroreceptor sensitivity (BRS) was tested in adult males, age-matched females, as well as ovariectomized (OVX) female rats by measuring the mean arterial pressure (MAP) in the presence of phenylephrine (PE) or sodium nitroprusside (SNP) $(2,5$, and $10 \mu \mathrm{g} / \mathrm{kg}$; Figure $1 \mathrm{~A} \& \mathrm{BB})$. Meanwhile, electrocardiogram (ECG) was monitored accordingly (Figure $1 \mathrm{C} \& 1 \mathrm{D})$. The results showed that the values of $\triangle \mathrm{HR} / \triangle \mathrm{MABP}$, an index of BRS, were dosedependently increased in females than that in males, and reversed completely back to the level of males in the OVX rats (Figure $1 \mathrm{E} \& 1 \mathrm{~F}$ ). This observation suggests that sex hormones may affect the function of catecholamines. The neuropeptide-Y (NPY), as a neurotransmitter and potent vasoconstrictor, influences sympathetic activation together with others including norepinephrine or angiotensinII [20]. In this regard, serum concentration of NPY was detected by ELISA, and no significant difference was observed between males and age-matched females (276.5 \pm 144.9 vs. $266.4 \pm 125.3 \mathrm{pg} / \mathrm{ml}, P>0.05, n=10)$. In addition, surgical removing of the ovaries did not affect serum NPY content $(279.5 \pm 98.6 \mathrm{pg} / \mathrm{ml} v s$. either males or females, $n=8$ ). These data suggested that serum NPY itself may not be the causal factor for the different baroreflex afferent function of males and female.

\section{Sex-specific and/or -estrogen $\left(17 \beta-E_{2}\right)$-dependent expression of $Y_{1} R$ and $Y_{2} R$ in nodose ganglia}

We then tested if there is any difference in the expression and distribution of NPY receptor between males and females. The protein expression of $Y_{1} R$ and $\mathrm{Y}_{2} \mathrm{R}$ was assessed in nodose ganglia (NG). The results showed that $\mathrm{Y}_{1} \mathrm{R}$ expression was lower $(P<0.01)$ in females compared with age-matched males, which was slightly but not significantly upregulated by ovariectomy $\left(P=0.116 v s\right.$. female). Nevertheless, $\mathrm{Y}_{1} \mathrm{R}$ was remarkably down-regulated by $17 \beta-\mathrm{E}_{2}$ treatment $(P<0.01$ or $P<$ 0.05 vs. male or OVX) (Figure 2A and 2C). Notably, the expression of $\mathrm{Y}_{2} \mathrm{R}$ was dramatically enhanced by OVX $(P<0.05$ vs. either male or female) and reversed $(P<$ 0.05 vs. OVX) by $17 \beta-\mathrm{E}_{2}$ treatment (Figure 2B and 2D) even though the expression level was identical between male and female rats. These observations suggest that the protein expression of both $\mathrm{Y}_{1} \mathrm{R}$ and $\mathrm{Y}_{2} \mathrm{R}$ are in a sexspecific or estrogen-dependent manner in the NG.

\section{Immunohistochemical analysis of $Y_{1} R$ and $Y_{2} R$ at tissue of nodose ganglia}

To further confirm the expression of NPY receptors in nodose ganglion, the immunohistochemical staining was carried out. Both $\mathrm{Y}_{1} \mathrm{R}$ (Figure 3) and $\mathrm{Y}_{2} \mathrm{R}$ (Figure 4) were detected in the cell-membrane and cytoplasm of myelinated afferents (HCN1-positive), whereas they were only detected in the cell-membrane of unmyelinated afferents (HCN1-nagetive, indicated as white arrowheads). 


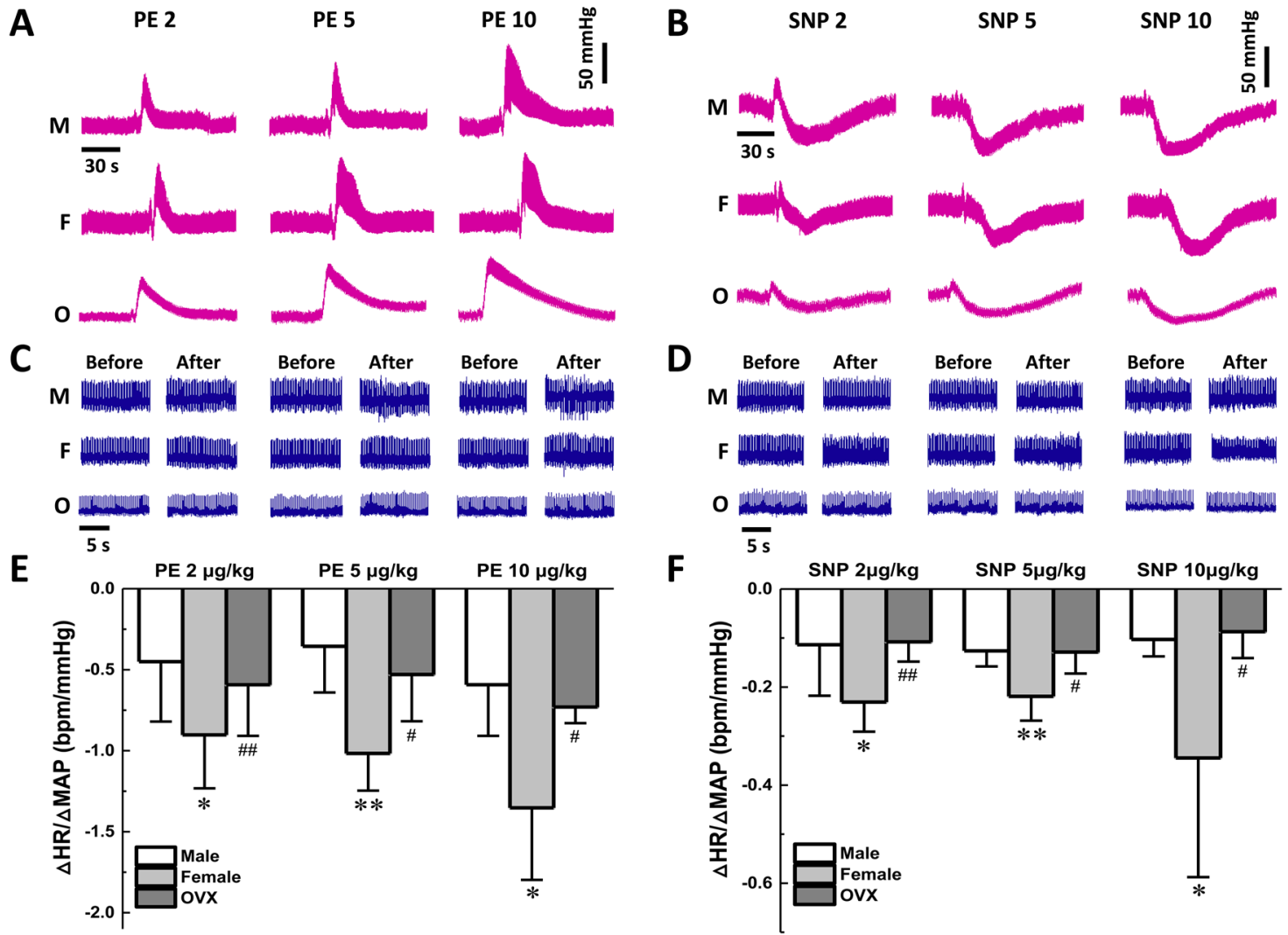

Figure 1: Effect on baroreflex sensitivity of gender difference during vasoactive drugs application. Femoral artery catheterization was applied to measure the change of MAP and venous cannula was used for administration of PE and SNP. A-B. The representative recordings of MAP collected from male (M; $n=7)$, female (F; $n=7)$, and ovariectomized (OVX; $n=4)$ rats in the presence of 2, 5, and $10 \mu \mathrm{g} / \mathrm{kg}$ of PE and SNP, respectively. C-D. The representative recordings of the heart rate (HR) along with the blood pressure (BP) changes; E-F. The summarized changes of BRS $(\triangle \mathrm{HR} / \triangle \mathrm{MABP}, \mathrm{bpm} / \mathrm{mmHg})$ when treated with PE and SNP at different concentration in each group. The averaged data were expressed as means $\pm \mathrm{SD} .{ }^{*} P<0.05$ and ${ }^{*} P<0.01 v$ s. Male group; ${ }^{*} P<0.05$ and ${ }^{* \#} P<0.01$ vs. Female group. Scale bars were applied for all recordings.

A

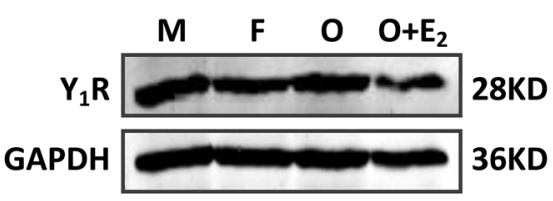

B

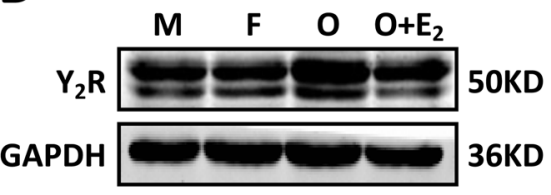

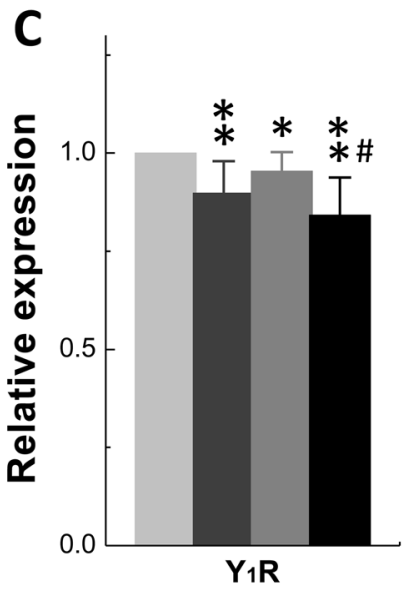

Figure 2: Gender difference in protein expression of $Y_{1} R$ and $Y_{2} R$ in Nodose Ganglia. Protein was accessed in nodose ganglia of adult male (M), aged-matched female (F), ovariectomized (OVX) female rats and OVX administrated 17ß-estradiol (17 $\left.\beta-E_{2}\right)$. A and $\mathbf{B}$. Protein bands for $Y_{1} R$ and $Y_{2} R$, respectively; $\mathbf{C}$ and $\mathbf{D}$. Averaged data of relative expression profiles for $Y_{1} R$ and $Y_{2} R$. The averaged data were presented as mean \pm SD. $n=4$ duplicated tests in which the tissue was collected from 10 rats of each group. ${ }^{*} P<0.05$ and ${ }^{* *} P<0.01$ vs. male, ${ }^{\#} P<0.05$ vs. OVX. 


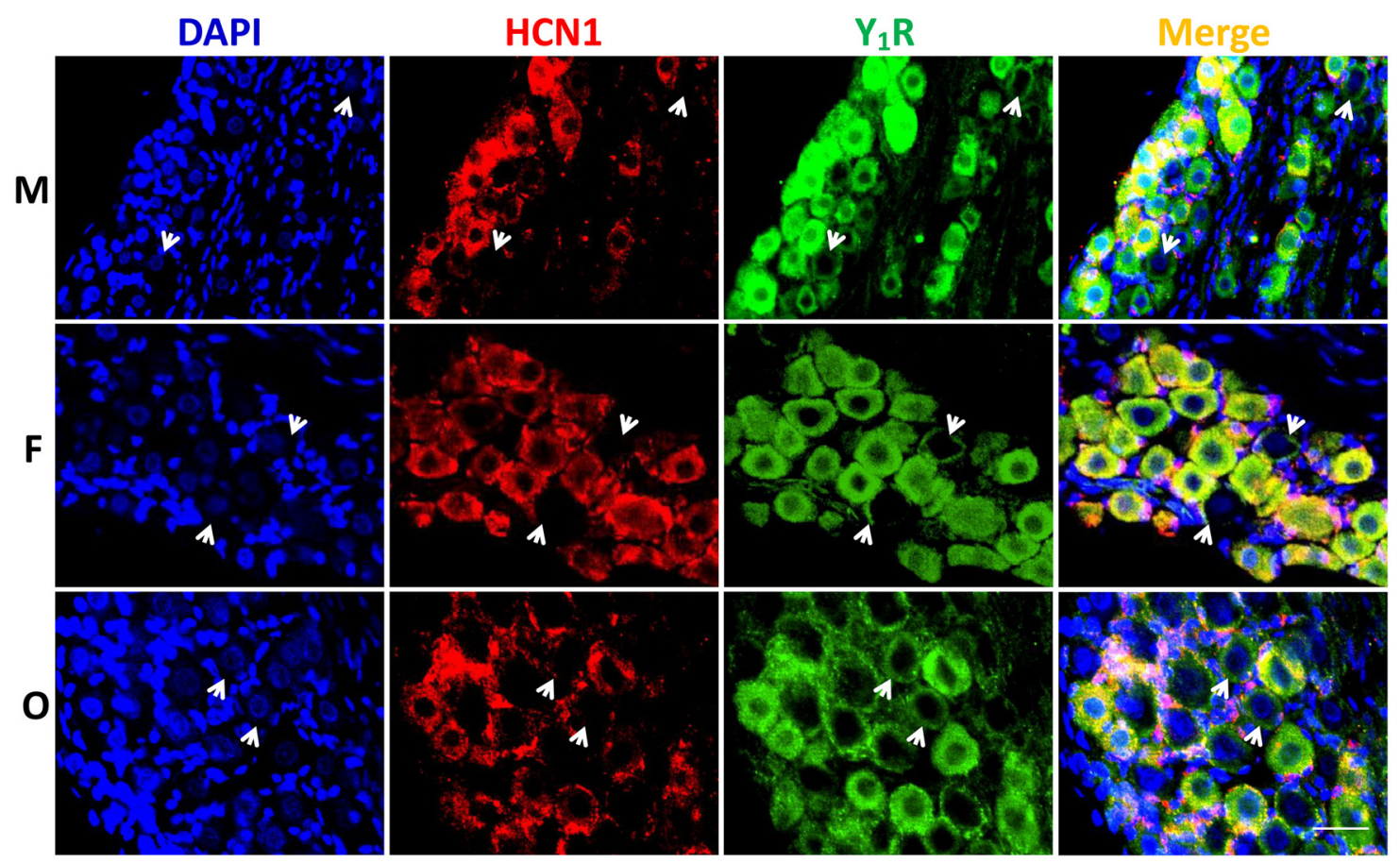

Figure 3: Immunohistochemical staining for $\mathbf{Y}_{1} \mathbf{R}$. The $\mathrm{Y}_{1} \mathrm{R}$ staining was performed in nodose ganglia from male (M, top), female (F, central), and ovariectomized (O, bottom) rats. The nucleus, hyperpolarization-activated channel specifically expressed on myelinated afferents (HCN1-positive), and $Y_{1} R$ were labeled by the antibodies against DAPI (blue), HCN1 (red), and $Y_{1} R$ (green). Arrowheads: indicate the neurons with unmyelinated afferents (HCN1-negative). The scale bar: $50 \mu \mathrm{m}$.

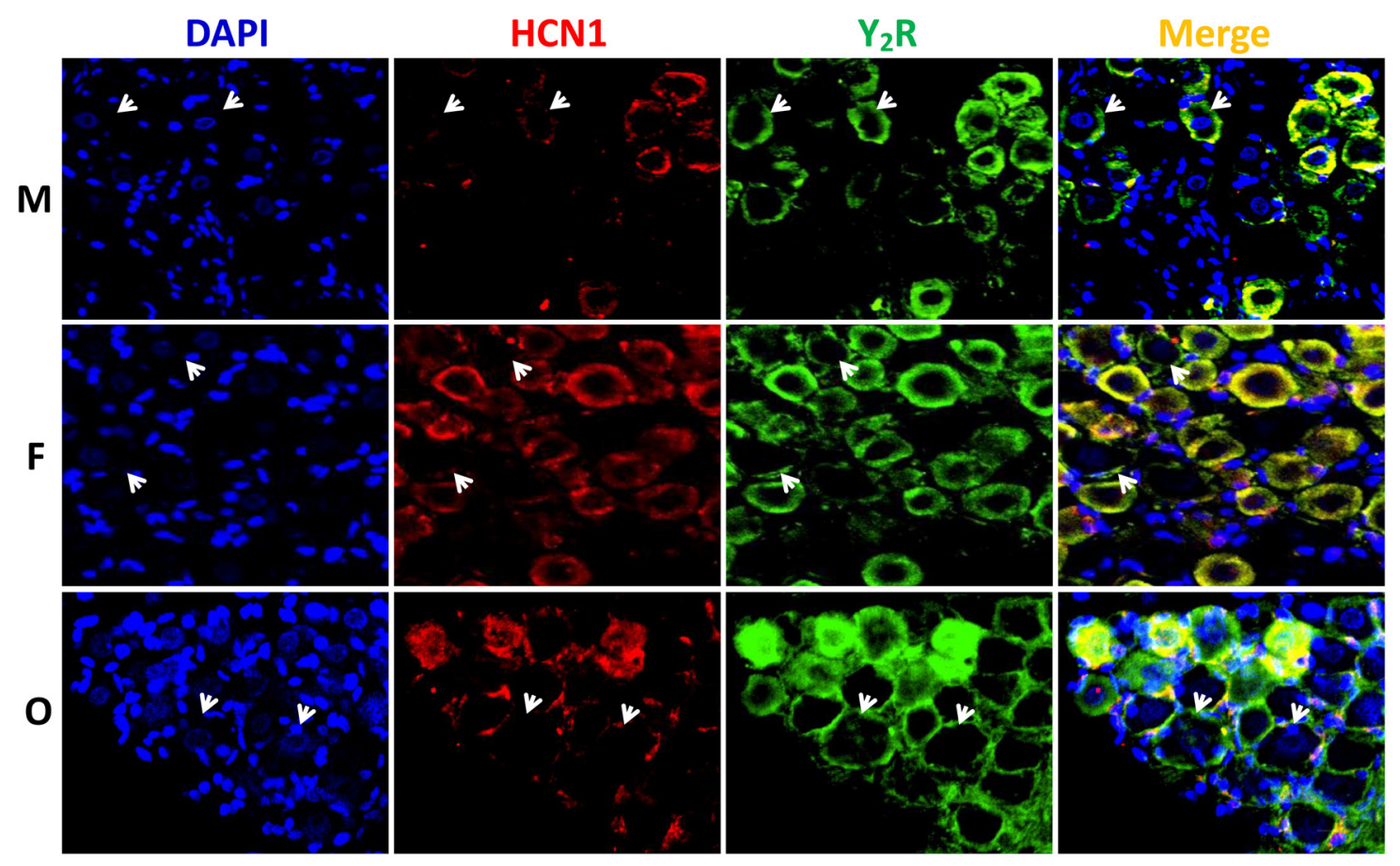

Figure 4: Immunohistochemical staining for $\mathbf{Y}_{2} \mathbf{R}$. The $\mathrm{Y}_{2} \mathrm{R}$ staining was performed in nodose ganglia from male (M, top), female (F, central), and ovariectomized $(\mathrm{O}$, bottom) rats. The nucleus, hyperpolarization-activated channel specifically expressed on myelinated afferents (HCN1-positive), and $\mathrm{Y}_{2} \mathrm{R}$ were labeled by the antibodies against DAPI (blue), HCN1 (red), and $\mathrm{Y}_{2} \mathrm{R}$ (green). Arrowheads: indicate the neurons with unmyelinated afferents (HCN1-negative). The scale bar: $50 \mu \mathrm{m}$. 
Quantification analysis (Supplementary Table S1) showed that, for $\mathrm{Y}_{1} \mathrm{R} / \mathrm{HCN} 1$-positive, the fluorescent intensity was lower in female $(P<0.05$ vs. male), which was further downregulated by OVX $(P<0.01 v s$. female). There was no difference between males and age-matched females in $\mathrm{Y}_{2} \mathrm{R} / \mathrm{HCN} 1$-positive, OVX dramatically upregulated $\mathrm{Y}_{2} \mathrm{R}$ level $(P<0.01 v s$. female). In the case of HCN1-negative populations, the difference in fluorescent intensity for $Y_{1} R$ was not established among groups. However, the intensity for $\mathrm{Y}_{2} \mathrm{R}$ of females was higher $(P<0.05 v s$. male $)$ and completely reversed by OVX $(P<0.01 v s$. female). Even though the averaged results of fluorescent analysis do not completely match with molecular observations, the difference might be explained by the YR whole tissue detection in molecular analysis and the afferent-specific quantification in fluorescence. The YR expression in cells other than neurons such as the satellite cells around the neurons (as indicated by the pink area of merged images from Figure 3 and 4) in the tissue of NG may also significantly influence the final analysis.

\section{Afferent-specific distribution of $Y_{1} R$ and $Y_{2} R$ in identified single BRNs from female rats}

To determine the afferent-specific expression, single-cell RT-PCR was employed in identified single BRNs. The data (Figure 5A) showed that $\mathrm{Y}_{1} \mathrm{R}$ mRNA equally expressed and distributed $(5 / 23$ or $5 / 25)$ in A- and C-types, whereas very low expression level of $\mathrm{Y}_{1} \mathrm{R}$ was found in only 1 of 22 tested Ah-type BRNs (1/22, Figure $5 \mathrm{~A} \&$ bottom tab.), indicating almost no $\mathrm{Y}_{1} \mathrm{R}$ expression in Ah-types. However, Ah- and C-types BRNs expressed more than 15 and 7 folds $(P<0.05$ vs. A-type) of $\mathrm{Y}_{2} \mathrm{R}$ (Figure $5 \mathrm{~B}$ ), respectively, even though the distribution in the number of positive detections was identical among A- $(\mathrm{n}=7 / 23,30.4 \%)$, Ah- $(\mathrm{n}=$ $7 / 22,31.8 \%$ ), and C-types (10/25, 40\%), suggesting a predominant role of $\mathrm{Y}_{2} \mathrm{R}$ in the function of $\mathrm{Ah}$ - and C-type BRNs (Figure 5 bottom tab.).

\section{$Y_{1} R$ and $Y_{2} R$ activation-mediated changes in blood pressure by nodose ganglion injection}

We then tested if $\mathrm{Y}_{1} \mathrm{R}$ and $\mathrm{Y}_{2} \mathrm{R}$ activation may produce opposite effects in $\mathrm{BP}$ regulation. The changes in mean arterial pressure (MAP) were investigated when NPY and selective agonists of $\mathrm{Y}_{1} \mathrm{R}$, Pro-34 and $\mathrm{Y}_{2} \mathrm{R}$, NPY13-36 were directly injected into NG (Figure 6). The results showed that both saline and $5 \mu \mathrm{g}$ of NPY placed right on the surface of NG did not induce significant changes in BP (Figure 6A top and bottom). However, in male rats, $5 \mu \mathrm{g}$ NPY and Pro-34 elevated BP dramatically (Figure 6B and 6C, top; $P<0.01$ vs. control), whereas 5 $\mu \mathrm{g}$ NPY-13-36 decreased BP (Figure 6D, top; $P<0.01$ vs. control). Most importantly, the averaged data (Figure 6E) showed that $\mathrm{Y}_{1} \mathrm{R}$-mediated BP elevations were stronger
(Figure 6B \& 6C, bottom tab., $P<0.01$ ) compared with females with either NPY or Pro-34, suggesting $\mathrm{Y}_{1} \mathrm{R}$ activation-mediated BP upregulation at the level of NG. Intriguingly, the sex-difference in $\mathrm{Y}_{2} \mathrm{R}$-mediated reduction of BP was not conformed and the effect of $Y_{1} R$ was much stronger than that of $Y_{2} R$, suggesting that $Y_{1} R$ and $Y_{2} R$ activation play an opposite action in $\mathrm{BP}$ regulation at the $1^{\text {st }}$-order neurotransmission of baroreflex afferent pathway, and NPY-mediated upregulation of BP by $\mathrm{Y}_{1} \mathrm{R}$ stimulation presumably masks $\mathrm{BP}$ downregulation due to its $\mathrm{Y}_{2} \mathrm{R}$ activation.

\section{$Y_{1} R$ or $Y_{2} R$-mediated similar down-regulation of neuromodulation in myelinated A-type BRNs by inhibition of presynaptic $\mathrm{Ca}^{2+}$ channel}

Upon the expression profile for $\mathrm{Y}_{1} \mathrm{R}$ in A-type BRNs, the effect of $Y_{1} R$ activation on action potential (AP) trajectory and N-type calcium currents $\left(I_{\mathrm{Ca}}\right)$ was investigated. Firstly, Y R activation by Pro34 (100 $\mathrm{nM}), \mathrm{Y}_{1} \mathrm{R}$ selective agonist, showed no effects on AP waveshape and discharge profiles (Figure 7A-7C) but significantly reduced current density of $I_{\mathrm{Ca}}$ with equal efficacy of $300 \mathrm{nM} \omega-\mathrm{CTX}$. The current was completely blocked by BIBP3226 (300 nM), a $\mathrm{Y}_{1} \mathrm{R}$ selective antagonist and PTX $100 \mathrm{nM}$, the blocker for G-protein coupled receptor, respectively (Figure 7D-7G). Even though AP discharge was not changed in the presence of Pro34, Y R activation-mediated reduction in current density of $I_{\mathrm{Ca}}$ may still change the neurotransmission in NTS due perhaps to the similar membrane structure between soma and its pre-synapse [21]. Similar results were also observed by $\mathrm{Y}_{2} \mathrm{R}$ activation in separate set of A-type BRNs under the same experimental condition (Data not shown). This phenomenon may attribute to lacking of the co-localization between $\mathrm{KCa} 1.1$ and $\mathrm{N}$-type $\mathrm{Ca}^{2+}$ channels in myelinated A-type cells even though the expression of theses channels could be identified.

\section{$\mathrm{Y}_{2} \mathrm{R}$-mediated peripheral and integrations in sex-specific and low-threshold myelinated $\mathrm{Ah}$ - type BRNs by presynaptic BK-KCa inactivation}

Compared with A-types, a presumed leading role of $\mathrm{Y}_{2} \mathrm{R}$ in sexual dimorphism in BRx afferent function is expected considering its extremely higher expression in low-threshold and sex-specific myelinated Ah-type BRNs (Figure 5). In electrophysiological identified Ah-types (Figure 7A-7B), $\mathrm{Y}_{2} \mathrm{R}$ activation by NPY1336 (100 nM), a selective $\mathrm{Y}_{2} \mathrm{R}$ agonist, markedly prolonged AP duration $\left(\mathrm{APD}_{50}\right)$ and slowed the maximal downstroke velocity $\left(\mathrm{DV}_{\mathrm{MAX}}\right)$ with increase in AP firing frequency (APFF) (Figure 8A-8F), notably broadened the frequency-dependent APD (Figure 8G-8I) and inhibited N-type $I_{\mathrm{Ca}}$ (Figure $8 \mathrm{~J}-8 \mathrm{M}$ ). These data imply 
that the increased APD may allow more presynaptic $\mathrm{Ca}^{2+}$ influx and lead to more neurotransmitter release. This hypothesis seems reasonable, but $\mathrm{Y}_{2} \mathrm{R}$ activation caused $I_{\mathrm{Ca}}$ inhibition may also directly reduce the $\mathrm{Ca}^{2+}$ influx at presynaptic membrane leading to an opposite action on neurotransmission. Therefore, additional investigations would definitely be necessary.

\section{$Y_{1} R$ - and $Y_{2} R$-mediated similar neuromodulation in unmyelinated baroreceptor afferents}

In electrophysiological identified unmyelinated C-type BRNs, Y R (Figure 9A-9C) and $\mathrm{Y}_{2} \mathrm{R}$ (Figure 9D9F) activation caused a similar $\mathrm{APD}_{50}$ prolongation and total inward current reduction as revealed by displacement current of phase plots with the decrease in the current density of $I_{\mathrm{Ca}}$. In the presence of Pro34 and NPY16-36, the APFF was increased with an activity-dependent AP broadening. (Supplementary Table S2).

\section{Sexual- and estrogen $\left(17 \beta-E_{2}\right)$-dependent expression of $Y_{1} R$, rather than $Y_{2} R$ in NTS}

The NTS is the center converged visceral afferent inputs from Vagus and aortic depressor nerve (ADN) relayed at the NG. The clarification of the expression and distribution of $Y_{1} R$ and $Y_{2} R$ in NTS would be critical for fully understanding of NPY-mediated sexual dimorphism in neurocontrol of circulation. To answer this question, the tissue of NTS were collected from adult male, agematched female, and OVX rats for the immunoblot study. The data (Figure 10) indicated that the expression of $\mathrm{Y}_{1} \mathrm{R}$, rather than $\mathrm{Y}_{2} \mathrm{R}$ is sex-specific and estrogendependent. $\mathrm{Y}_{1} \mathrm{R}$ expression in females was $161.7 \%(P$ $<0.05$ ) compared with male group, and was completely downregulated in OVX to the equivalent level to males (Figure 10C). The mRNA expressions of $\mathrm{Y}_{1} \mathrm{R}$ and $\mathrm{Y}_{2} \mathrm{R}$ were also tested and identical expression pattern was observed (data not shown).
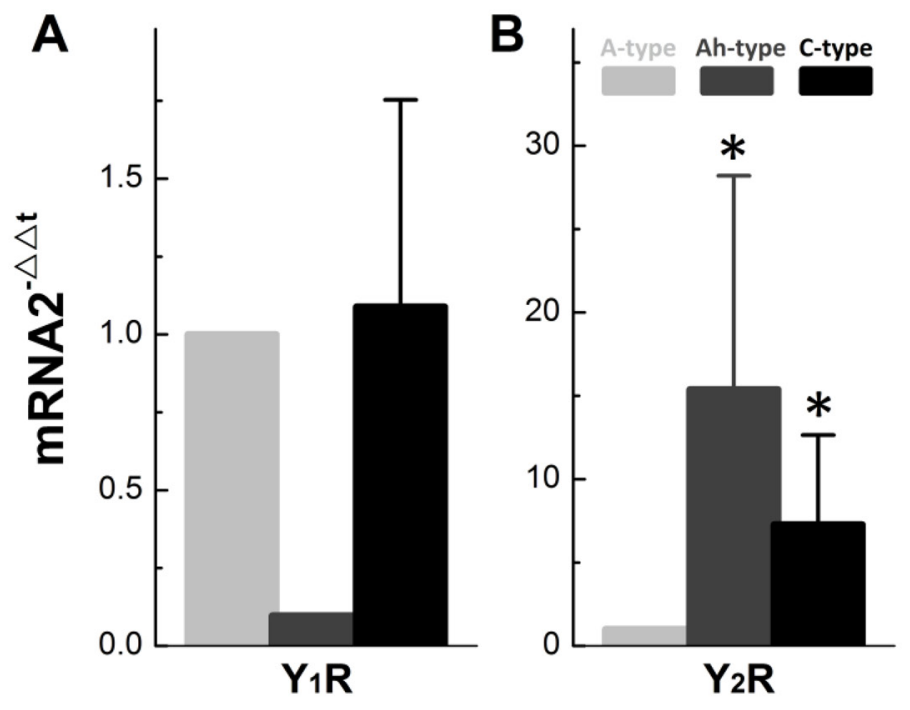

\begin{tabular}{|l|c|c|c|}
\hline Summary & $\mathbf{A}=\mathbf{2 3}$ & $\mathbf{A h}=\mathbf{2 2}$ & $\mathrm{C}=\mathbf{2 5}$ \\
\hline $\mathbf{Y}_{1} \mathbf{R}$ & 5 & 1 & 5 \\
\hline $\mathbf{Y}_{2} \mathbf{R}$ & 7 & 7 & 10 \\
\hline $\mathbf{Y}_{1} \mathbf{R}+\mathbf{Y}_{2} \mathbf{R}$ & & 1 & 1 \\
\hline Negative & 11 & 14 & 10 \\
\hline Positive & $52.2 \%$ & $36.4 \%$ & $40.0 \%$ \\
\hline Total positive & & $\mathbf{5 0 . 0 \%}$ & \\
\hline
\end{tabular}

Figure 5: Cell-specific expression and distribution of $m R N A$ of $Y_{1} R$ and $Y_{2} R$ in identified single $B R N s$ from adult female rats. The action potential (AP) was collected under the current-clamp mode of whole-cell configuration and the afferent fiber types of BRNs was identified by standard electrophysiological validation, which was then collected for single-cell RT-PCR. A. Relative mRNA expression of $Y_{1} R ;$ B. Relative mRNA expression of $Y_{2} \mathrm{R} ; n=22-25 .{ }^{*} P<0.05 v s$. A-type BRNs. The bottom table: the percentage distribution of $Y_{1} R$ and $Y_{2} R$ in each category neurons. 


\section{DISCUSSION}

The major contribution of the current investigation is to demonstrate for the first time that sex- and afferent-specific expression and distribution of $Y_{1} R$ and $Y_{2} R$ are observed in baroreflex afferent pathway including NG and NTS by the use of immunoblotting and immunohistochemistry, as well as single-cell RT-PCR technique in identified baroreceptor neurons. Additionally, activation of $Y_{1} R$ and $Y_{2} R$ mediate differential neuroexcitation and $\mathrm{Ca}^{2+}$ channel modulation in myelinated A-, Ah- and unmyelinated C-type BRNs identified by electrophysiological validations. These results suggest that NPY and its receptor system play a crucial role in sexual dimorphism of BRx afferent function and neurocontrol of $\mathrm{BP}$ regulation.
Increasing body of evidence has demonstrated that NPY receptor expresses in both CNS [22] and PNS [23] and is involved in gender-mediated regulation of BP [1] and hypertension [7]. Previous researches [24, 25] have suggested that NPY is co-stored and co-released with norepinephrine (NE) and other catecholamines in adrenal medulla or from the postganglionic sympathetic nerves to influence the cardiovascular system and correlates with sympathetic activation [26]. However, they do not always have the synergistic action to influence hemodynamic effects. Especially in coronary and cerebral vessels, NPY induces significantly vasoconstriction where NE is not effective $[27,28]$. Our present data demonstrated a dramatic sex- and estrogen-related difference in BRS with identical serum concentration of NPY among male, age-
A

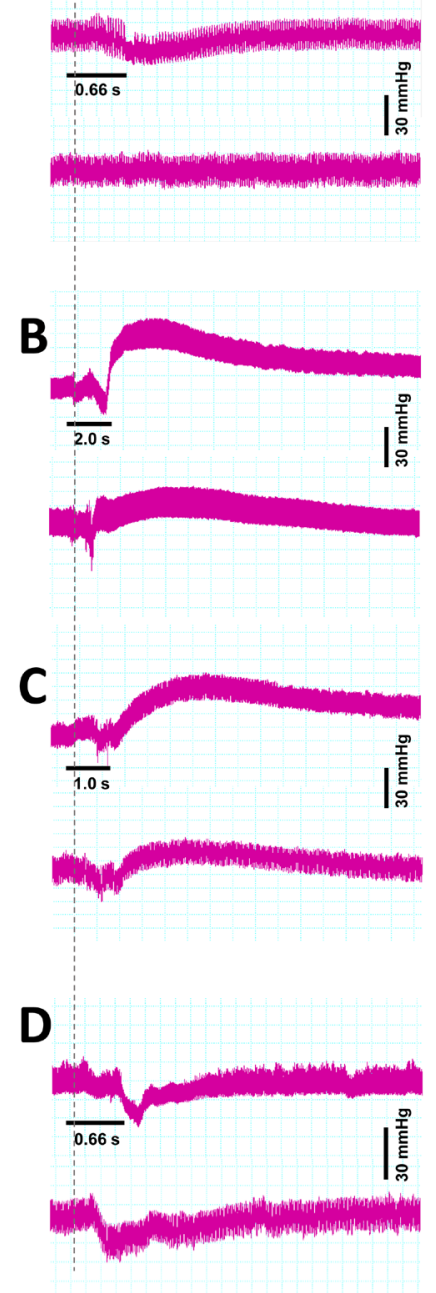

E

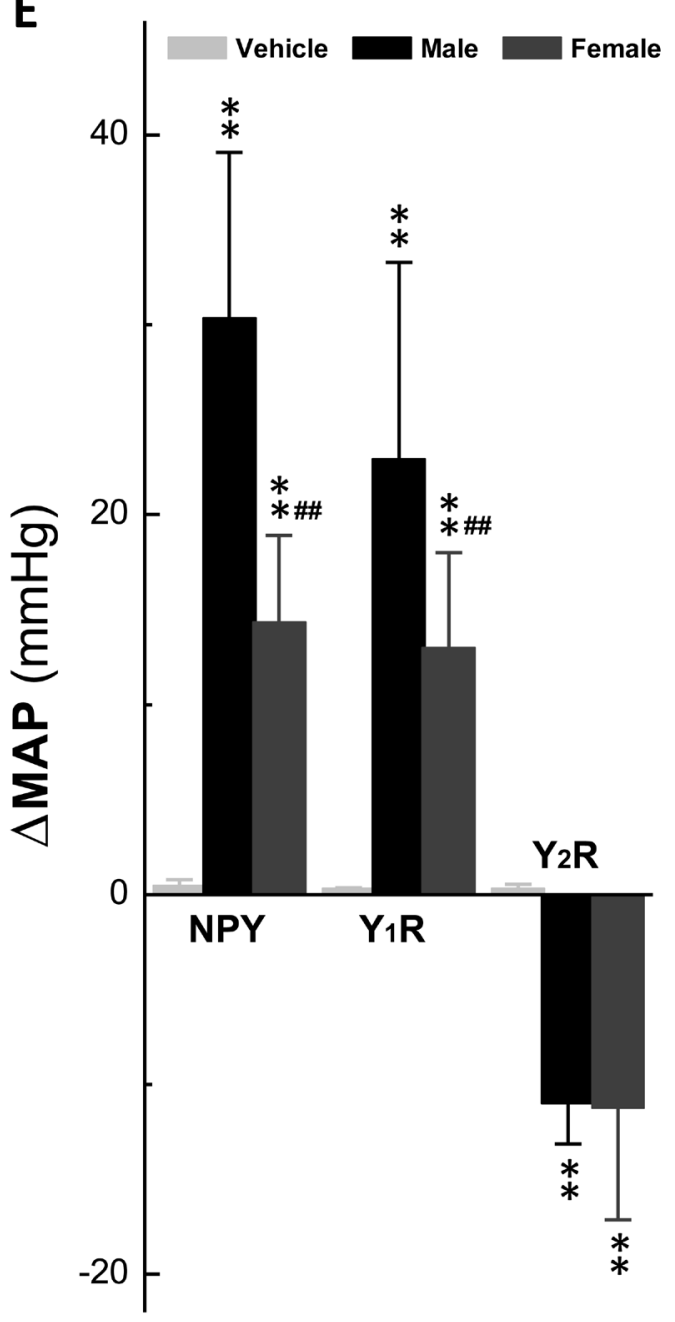

Figure 6: $Y_{1} R$ and $Y_{2} R$ activation-mediated changes in blood pressure by NG microinjection. The left side of nodose ganglion (NG) and Vagus were dissected and exposed carefully on anesthetic rats. The femoral artery cannulation was performed and the blood pressure (BP) was collected before and after administration of $5 \mu \mathrm{g}$ NPY, Pro-34, and NPY13-36, respectively. A. the representatives of BP recordings before and after saline (top) and NPY placed on the surface (bottom) of NG; B-D. representative of BP recordings before and after NPY, Pro-34, and NPY13-36, respectively, in male (top) and female rats (bottom); The dash line indicates the time of the beginning of treatment. E. the summarized changes in the net mean arterial pressure ( $\triangle \mathrm{MAP})$ before and after each treatment in male $(n=6)$ and female $(n=6)$ rats. The averaged data were expressed by mean $\pm \mathrm{SD} . * * P<0.01$ vs. vehicle control, ${ }^{\#} P<0.01$ vs. male group. 
matched female, and ovariectomized female rats. This observation implied that NPY may influence BRx afferent function by the differential expression of its receptor subtypes in NG and NTS. The present study indicated that the sex-specific lower expression of $\mathrm{Y}_{1} \mathrm{R}$ in females and the upregulation by lacking of estrogen at NG level, which may explain at least partially why the BP is lower in females vs. age-matched males and significantly increased by OVX procedure observed in our previous observation [29]. These data are also consistent with the notion that $\mathrm{Y}_{1} \mathrm{R}$ mediates significant sympathetic vasoconstriction $[30,31]$. Although the $\mathrm{Y}_{2} \mathrm{R}$ expression is not sex-specific, it was upregulated by OVX procedure and downregulated by estrogen treatment. Considering that $\mathrm{Y}_{1} \mathrm{R}$ and $\mathrm{Y}_{2} \mathrm{R}$ often mediate an opposite response of MAP in the present study (Figure 6) and work from others [5], the peripheral compensatory mechanism may exist to counteract the $\mathrm{Y}_{1} \mathrm{R}$-mediated vasoconstriction and elevated $\mathrm{BP}$ in OVX via overexpression of $\mathrm{Y}_{2} \mathrm{R}$. Upregulation of $\mathrm{Y}_{2} \mathrm{R}$ has also been confirmed in the rat model of heart failure [32] and may be well explained by the evidence of parasympathetic vasodilation through presynaptic expression of $\mathrm{Y}_{2} \mathrm{R}$.

The sex-difference in $\mathrm{Y}_{1} \mathrm{R}$ and $\mathrm{Y}_{2} \mathrm{R}$ expressions has been confirmed in the tissue level of NG. However, the afferent-specific expression of these receptors needs to be clarified to fully understand the cellular mechanism of NPY. Due to the multiple afferent neuron types, the single-cell RT-PCR [29, 33] would be the best to detect mRNA expression in electrophysiologically identified individual neurons [13]. The result has demonstrated the positive detection for A-, Ah, and C-BRNs are 52.2\%, $36.4 \%$, and $60 \%$, respectively; and the ratios of $Y_{1} R /$ $\mathrm{Y}_{2} \mathrm{R}$ for A-, Ah, and C-BRNs are 5/7, 1/7, and 5/10 as well. Interestingly, $\mathrm{Y}_{2} \mathrm{R}$ not only expresses at higher level but also distributes predominantly in low-threshold and sex-specific subpopulation of Ah-BRNs, suggesting a dominant role of Ah-BRNs in sexual-dimorphism of BRx afferent function. Even though $\mathrm{Y}_{1} \mathrm{R}$ equally expresses in A- or C-BRNs, its expression level is only about $1 / 10$ th in Ah-BRNs. In stark contrast, the expression level for
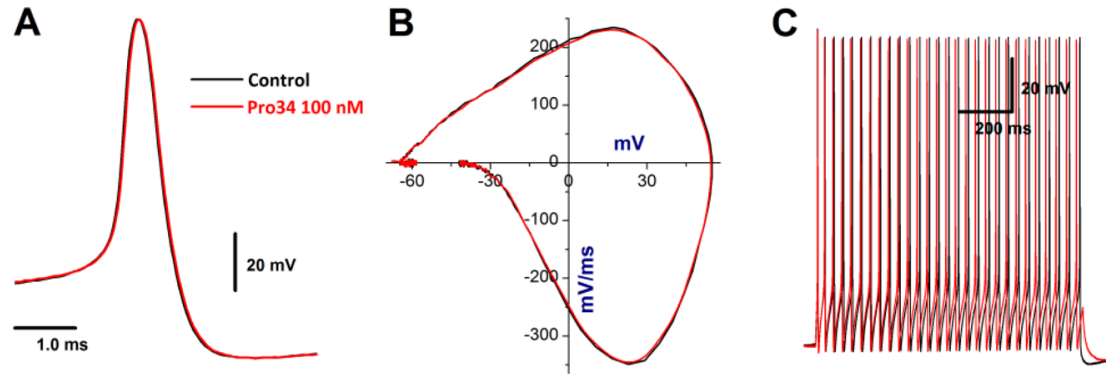

\begin{tabular}{|l|c|c|c|c|c|c|}
\hline$n=8$ & RPM & APFT & APD $_{50}$ & UV $_{\text {MAX }}$ & DV $_{\text {MAX }}$ & APFF \\
\hline Control & $61.4 \pm 3.26$ & $-45.2 \pm 5.12$ & $0.79 \pm 0.07$ & $342 \pm 36$ & $225 \pm 27$ & $32.6 \pm 6.12$ \\
\hline Pro34 & $60.9 \pm 3.88$ & $-46.0 \pm 4.78$ & $0.78 \pm 0.80$ & $344 \pm 39$ & $220 \pm 31$ & $33.1 \pm 5.14$ \\
\hline
\end{tabular}
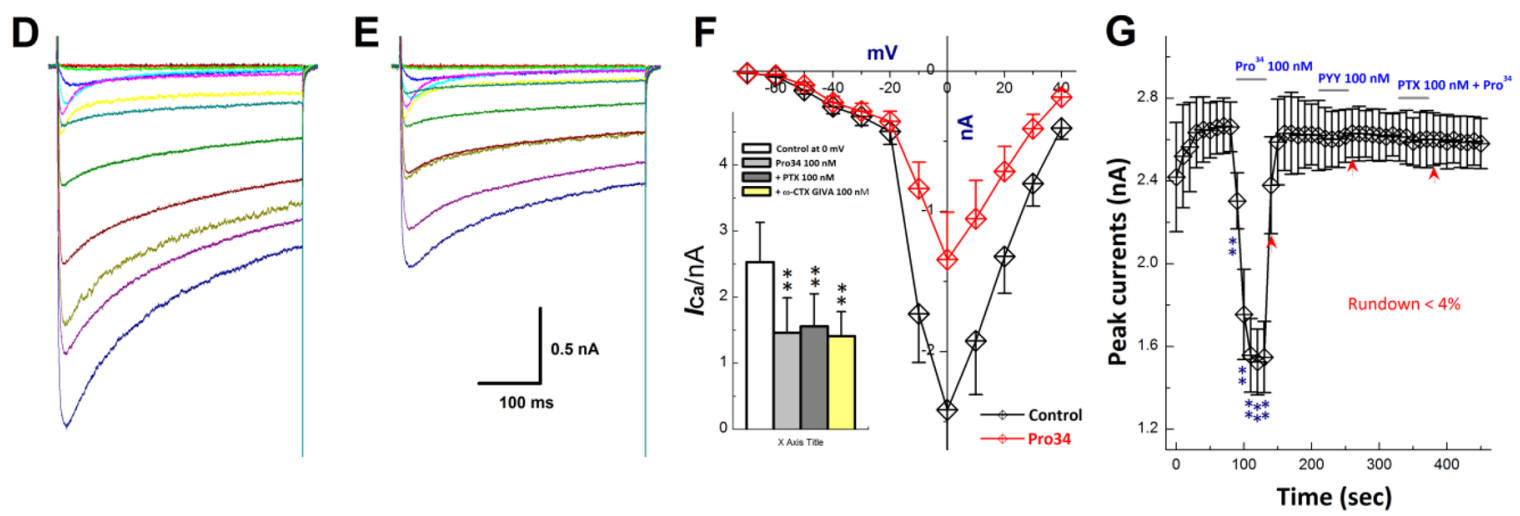

Figure 7: Effects of Pro34 on AP discharge profiles and $\boldsymbol{I}_{\mathrm{Ca}}$ in identified A-type BRNs. A-B. action potential (AP) and derivative changes before and after $100 \mathrm{nM}$ Pro34; C. repetitive discharge before and after Pro34; Center table: summarized changes in AP discharge profiles; D-E. the $\mathrm{Ca}^{2+}$ current $\left(I_{\mathrm{Ca}}\right)$ in identified A-BRNs using slice preparation before and after Pro34; F. current-voltage relationship (I-V) of $I_{\mathrm{Ca}}$ before and after Pro34, inset: averaged data of I-V with different treatments, $n=6-7, * * P<0.01 v s$. control at $0 \mathrm{mV}$; G. time course of $I_{\mathrm{Ca}}$ alternations in the presence of Pro34, $300 \mathrm{nM}$ BIBP3226 (Y, R antagonist) + Pro34, and $100 \mathrm{nM}$ pertussis toxin (PTX) + Pro34, respectively, $n=5$ complete recordings, $* P<0.05$ and $* * P<0.01$ vs. before. Scale bars in (E) also apply for (D). 
$\mathrm{Y}_{2} \mathrm{R}$ is more than 15 or 7 folds higher in Ah-BRNs than that in A- or C-BRNs. This novel finding for the first time demonstrated that the afferent-specific expression profiles of $Y_{1} R$ and $Y_{2} R$ and the likely role of $Y_{1} R$ and $Y_{2} R$ in the neurocontrol of circulation and $\mathrm{BP}$ regulation at the cellular and molecular levels of BRx afferent pathway.

From the functional point of view, $\mathrm{Y}_{1} \mathrm{R}$ or $\mathrm{Y}_{2} \mathrm{R}$ activation-mediated neuroexcitation and underlying ion channel mechanism are the further questions to be answered. For A-type BRNs, Y R activation did not alter the AP trajectory but significantly decreased the $I_{\mathrm{Ca}}$ density, suggesting that N-type $I_{\mathrm{Ca}}$ is not involved in the formation of AP waveform [34] or the coupling between KCa1.1 [35] and $\mathrm{N}$-type $\mathrm{Ca}^{2+}$ channel although both $\mathrm{KCa} 1.1 \alpha-$ and $\beta 4$ - subunits were identified [36]. This observation suggests that NPY may be not critical for the neuroexcitation of A-types but play some role in cell signaling through $I_{\mathrm{Ca}}$ modulation. Whereas, for C-type BRNs, due to the significant higher expression of $\mathrm{Y}_{2} \mathrm{R}$ observed by singlecell data and large number of its population compared with A-BRNs, somewhat important roles in sex-specific neuromodulation at BRx afferent pathway would be expected.

Since the sex-specific distribution [12], the key role in BRx afferent function [19], unique higher expression of $\mathrm{Y}_{2} \mathrm{R}$ from the current observation, and the effect of $\mathrm{Y}_{1} \mathrm{R}$ or $\mathrm{Y}_{2} \mathrm{R}$ activation on the neuroexcitation of Ah-type BRNs would be the key explanation for the sex-dimorphic BRx.
A

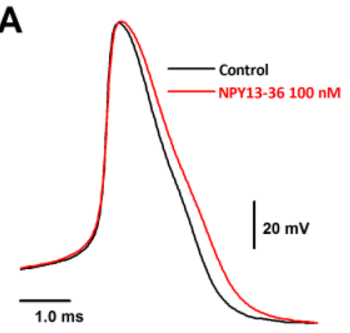

$\mathbf{F}$

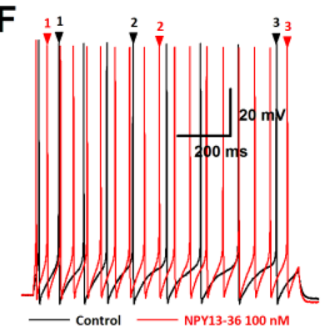

B

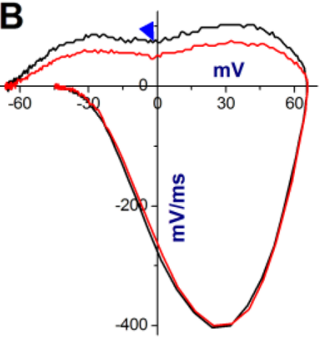

G

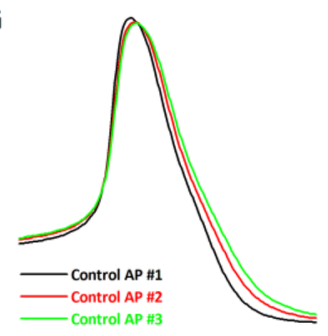

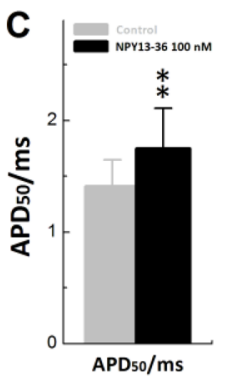

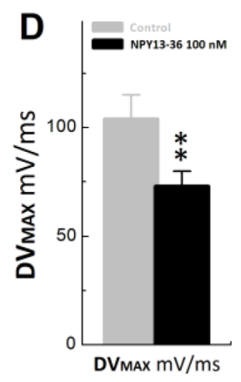

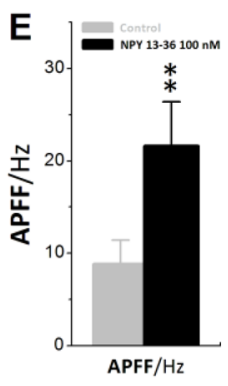

H
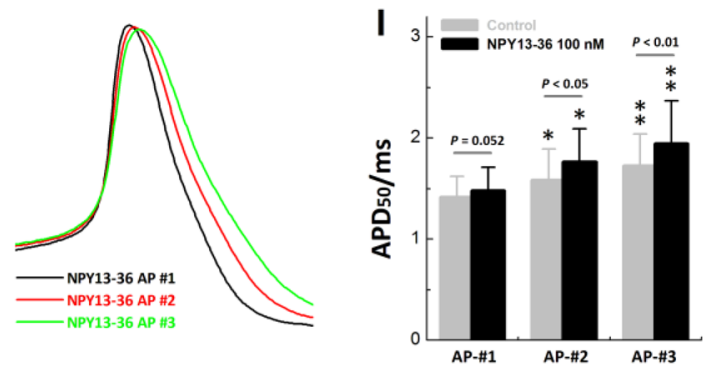
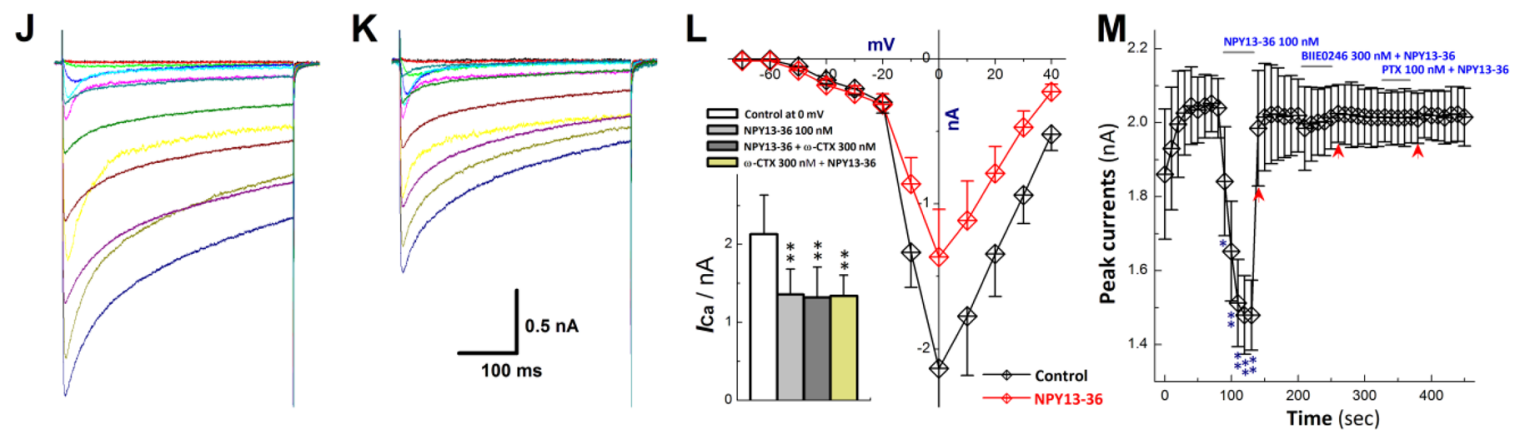

Figure 8: Effects of NPY13-36 on AP discharge profiles and $\boldsymbol{I}_{\mathrm{Ca}}$ in identified Ah-type BRNs. A-B. action potential (AP) and derivative changes before and after $100 \mathrm{nM}$ NPY13-36; C-E. summarized changes in $\mathrm{APD}_{50}, \mathrm{DV}_{\mathrm{MAX}}$, and APFF in the presence of NPY13-36, $n=6-10, * * P<0.01$ vs. control; F. repetitive discharge before and after NPY13-36; G-H. frequency-dependent prolongation of $\mathrm{APD}_{50}$ by superimposition of APs pointed by arrows with numbers during repetitive firings before and after NPY13-36; I. averaged data for frequency-dependent prolongation, $n=7, * P<0.05$ and $* * P<0.01 v s$. control; $\mathbf{J}-\mathbf{K}$. whole-cell Ca ${ }^{2+}$ currents $\left(I_{\mathrm{Ca}}\right)$ recorded in Ah-types identified by the conduction velocity (CV) using slice preparation before and after NPY13-36; $\mathbf{L}$. current-voltage relationship (I-V curve) of $I_{\mathrm{Ca}}$ before and after NPY13-36, inset: averaged data of I-V with different treatments, $n=5-7, * * P<0.01 \mathrm{vs}$. control at $0 \mathrm{mV}$; M. time course of $I_{\mathrm{Ca}}$ alternations in the presence of NPY13-36, $300 \mathrm{nM} \mathrm{BIIE0246} \mathrm{(Y,R} \mathrm{antagonist)} \mathrm{+} \mathrm{NPY13-36,} \mathrm{and} 100 \mathrm{nM}$ pertussis toxin (PTX) + NPY13-36, respectively, $n=5$ complete recordings, $* P<0.05$ and $* * P<0.01 v s$. control. Scale bars in (A) also apply for (G-H); scale bar in (K) also apply for $(\mathrm{J})$. 
A

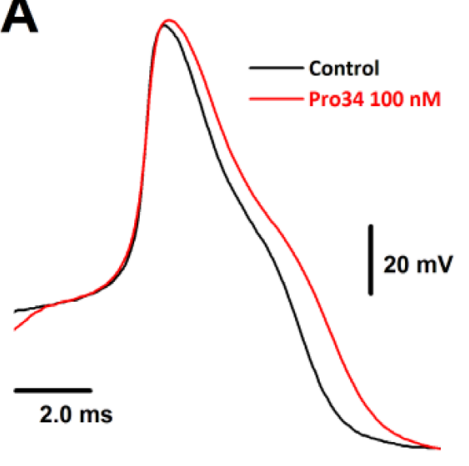

D

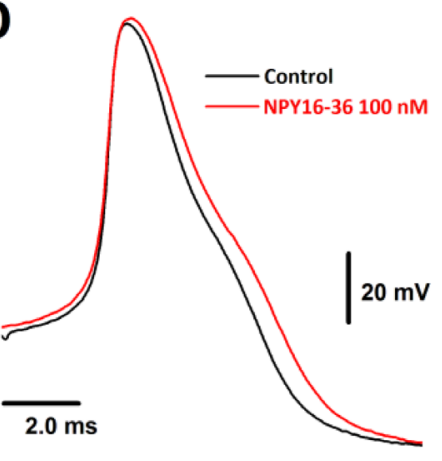

B

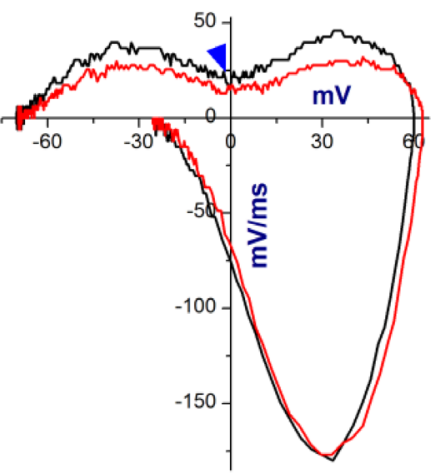

$\mathbf{E}$

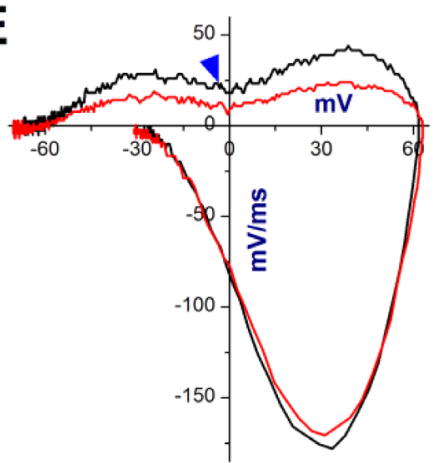

C

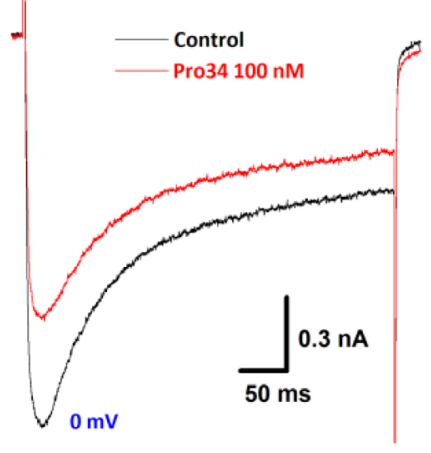

$\mathbf{F}$

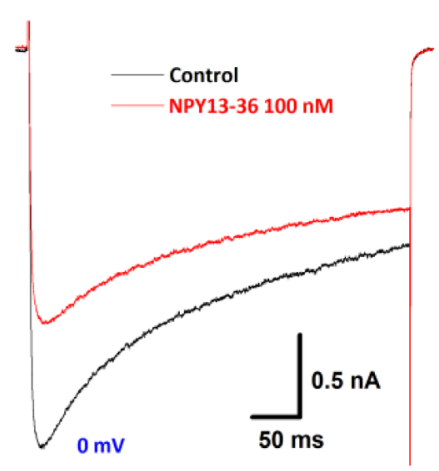

Figure 9: Effects of directly $Y_{1} R$ and $Y_{2} R$ stimulation on $A P$ and $I_{C a}$ in identified C-type BRNs. A-B. action potential (AP) and derivatives before and after $Y_{1} R\left(100 \mathrm{nM}\right.$ Pro34); C. representative recordings of $\mathrm{Ca}^{2+}$ currents $\left(I_{\mathrm{Ca}}\right)$ at $0 \mathrm{mV}$ before and after $100 \mathrm{nM}$ Pro34; D-E. AP and derivatives before and after $Y_{2} \mathrm{R}$ activation (100 nM NPY13-36); F. representative recordings of $I_{\mathrm{Ca}}$ at $0 \mathrm{mV}$ before and after $100 \mathrm{nM}$ NPY13-36. The center of repolarization hump is indicated by $(\boldsymbol{\nabla})$.
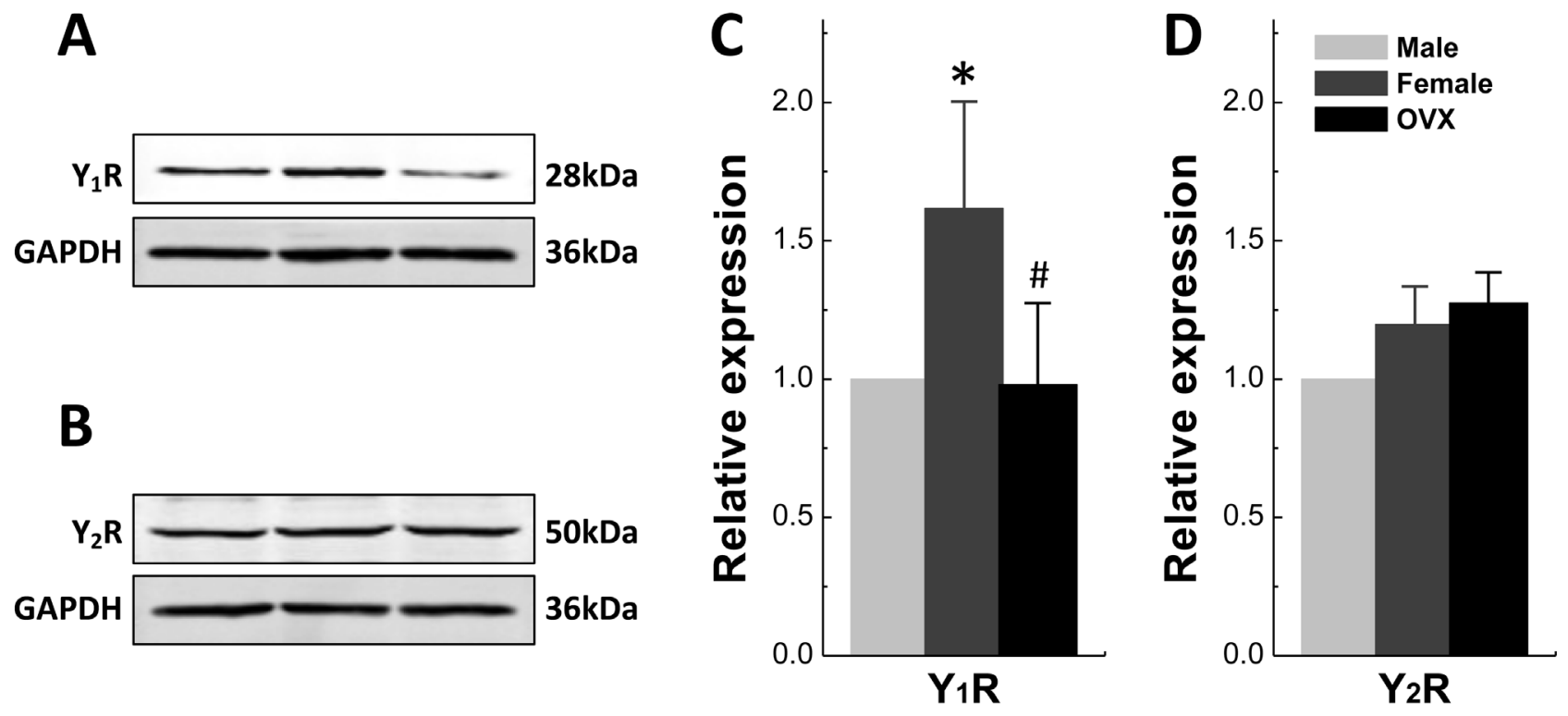

Figure 10: Protein Expression of $Y_{1} \mathbf{R}$ and $\mathbf{Y}_{\mathbf{2}} \mathbf{R}$ in Nucleus of Tractus Solitarii. Protein expression was accessed in tissue of nucleus of tractus solitarii (NTS) collected from adult male, aged-matched female, ovariectomized (OVX) female rats. A and B. Protein bands for $\mathrm{Y}_{1} \mathrm{R}$ and $\mathrm{Y}_{2} \mathrm{R}$, respectively; $\mathbf{C}$ and $\mathbf{D}$. Averaged data of relative expression profiles for $\mathrm{Y}_{1} \mathrm{R}$ and $\mathrm{Y}_{2} \mathrm{R}$. The averaged data were presented as mean $\pm \mathrm{SD} . n=4$ duplicated tests in which the tissue was collected from 6 rats of each group. ${ }^{*} P<0.05$ vs. male, ${ }^{\sharp} P<0.05$ vs. female. 
Therefore, by $\mathrm{Y}_{2} \mathrm{R}$ activation, the AP repolarization was significantly altered with longer $\mathrm{APD}_{50}$, slower $\mathrm{DV}_{\mathrm{MAX}}$, faster APFF, and lesser total outward $\mathrm{K}^{+}$currents from AP waveform and phase plots, respectively. Interestingly, activity- or frequency-dependent AP broadening [11, 37] was further enhanced in Ah-type BRNs by $Y_{2} R$ activation, rather than Y1R stimulation (data not shown), strongly suggesting the $\mathrm{Y}_{2} \mathrm{R}$ activation-mediated $\mathrm{KCa} 1.1$ inactivation $[35,36]$ indirectly due to $\mathrm{N}$-type $\mathrm{Ca}^{2+}$ channel inhibition through the coupling mechanism.

Even though intriguing observations from the cardiovascular literature have provided quantitative evidence that myelinated and unmyelinated cardiovascular afferents evoke not only different frequency-dependent reflex responses but also potential and distinctly different sensory information processing mechanisms [38, 39]. These differences could be explained at least partially by the sex- and afferent-specific expression of $Y_{1} R$ and $\mathrm{Y}_{2} \mathrm{R}$ and an opposite action of $\mathrm{Y}_{1} \mathrm{R}$ and $\mathrm{Y}_{2} \mathrm{R}$ activation in blood pressure regulation. Additionally, the difference in peripheral and central mechanism in neurocontrol of circulation mediated by NPY has been identified [3, 5, 20], manifested as a hypotensive and hypertensive responses by $\mathrm{Y}_{1} \mathrm{R}$ and $\mathrm{Y}_{2} \mathrm{R}$ activation in NTS (central), which was a stark contrast compared with by $\mathrm{Y}_{1} \mathrm{R}$ and $\mathrm{Y}_{2} \mathrm{R}$ activation in NG (peripheral). Even though the central hypotensive action of NPY is led by $\mathrm{Y}_{1} \mathrm{R}$ activation [20], the sex-dimorphism in NPY receptor expression is not elucidated so far in NTS. Apparently, averaged $Y_{1} R$ protein expression is markedly higher in females than that in age-matched male rats, which is downregulated by $\mathrm{OVX}$, and similar expression pattern for $\mathrm{Y}_{2} \mathrm{R}$ is detected in NTS. This result may contribute, at least in part, to the sexdifference in BP of animal [19, 29] and human [40] with an estrogen-dependent fashion. Moreover, we have a strong reason to believe that myelinated Ah-type barosensitive neurons housed in NTS $[41,42]$ to relay and integrative the sensory information of BP (Figure 11). The most importantly, the sex- and afferent-specific expression of $\mathrm{Y}_{1} \mathrm{R}$ and $\mathrm{Y}_{2} \mathrm{R}$ from this study would favor the explanation for the sex-difference in IbTX-mediated discharge profiles in the 1st-order BRNs $[11,36]$ of BRx pathway.

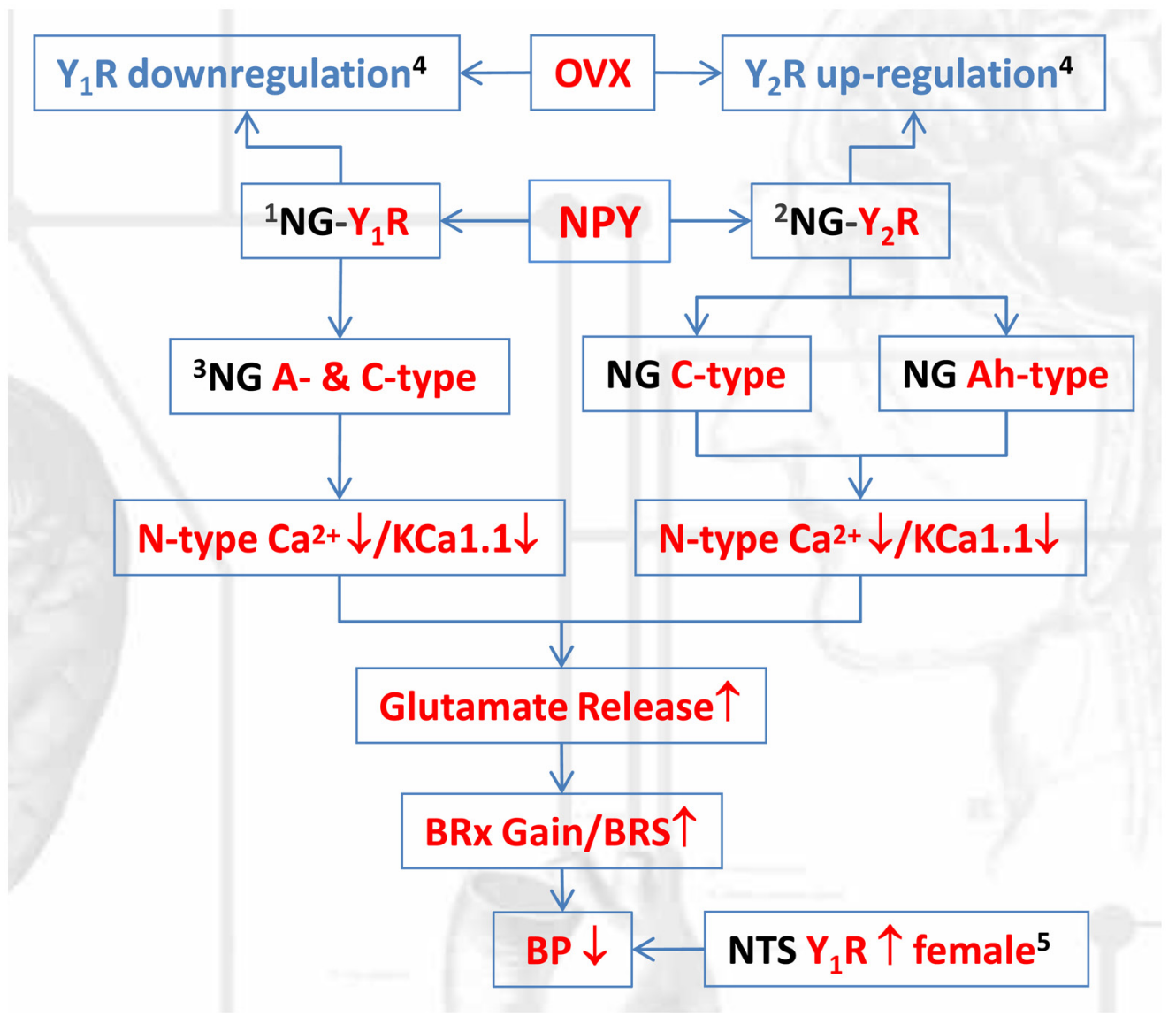

Figure 11: The schematic diagram regarding the cellular mechanism underlying neuropeptide Y-mediated sex- and afferent-specific neurotransmissions of blood pressure regulation. Notes for the superscript: (1). $Y_{1} R$ highly expressed in myelinated A-type BRNs; (2). Y R mainly expressed in myelinated Ah-type BRNs; (3). action potential duration (APD) was not altered by N-type $\mathrm{Ca}^{2+}$ channel inhibition but KCa1.1; (4). This action was restored by estrogen treatment; (5). $\mathrm{Y}_{1} \mathrm{R}$ expression in nucleus tractus solitarii (NTS) was opposite to that in nodose ganglia (NG). 
Although $\mathrm{Y}_{1} \mathrm{R}$ expression in tissue level of $\mathrm{NG}$ is slightly increased but statistical significance is not established between female and OVX model perhaps due to the smaller mass of ganglion tissue leading to a relatively large variation and supported by the notion that $\mathrm{Y}_{1} \mathrm{R}$ expression could be further downregulation after estrogen treatment. Whereas, in case of $Y_{2} R$, the expression is identical between sexes but the OVX-mediated upregulation is restored with the treatment of estrogen, implying that OVX led $\mathrm{Y}_{2} \mathrm{R}$ upregulation would be explained as the compensatory mechanism at NG level to counteract elevated $\mathrm{Y}_{1} \mathrm{R}$ expression when lacking of estrogen. In addition, immunofluorescence showed that the $\mathrm{Y}_{1} \mathrm{R}$ expression is further downregulated while $\mathrm{Y}_{2} \mathrm{R}$ upregulation in HCN1-positive populations and together with the opposite pressor response mediated by $\mathrm{Y}_{1} \mathrm{R}$ and $\mathrm{Y}_{2} \mathrm{R}$, the compensatory neuromodulation of NPY through its receptors in neurocontrol of circulation and $\mathrm{BP}$ regulation is sex-dimorphic and estrogen-dependent.

Taken together, we conclude that NPY would be a key player in either peripheral or central pathway in the regulation of blood pressure, and collaborative expression pattern between $\mathrm{Y}_{1} \mathrm{R}$ and $\mathrm{Y}_{2} \mathrm{R}$ at either NG or NTS level as well as an opposite pressor response of $\mathrm{Y}_{1} \mathrm{R}$ and $\mathrm{Y}_{2} \mathrm{R}$ would greatly impact on a sexual dimorphism of neurocontrol of circulation and BP.

\section{MATERIALS AND METHODS}

An expanded methods section is available in the online-only data supplement.

\section{Arterial baroreflex sensitivity}

Various doses of phenylephrine (PE) and sodium nitroprusside (SNP) were injected intravenously to measure the sex difference in baroreceptor sensitivity (BRS).

\section{Protein expression of $Y_{1} R$ and $Y_{2} R$}

Western Blot analysis was performed for testing relative expression of $\mathrm{Y}_{1} \mathrm{R}$ and $\mathrm{Y}_{2} \mathrm{R}$.

\section{Immunohistochemical staining}

Due to the afferent-specific expression, the antibody against for HCN1 was selected in this experiment as the fluorescent marker for myelinated afferents [16, 43], so, HCN1-positive and HCN-1-negative neurons were presumably classified as myelinated and unmyelinated afferents.

\section{Nodose ganglion microinjection of NPY and its receptor agonists}

As described in the literature [44], after recording the baseline (before surgery) of blood pressure, the left side NG was exposed and $2 \mu \mathrm{l}$ saline as the vehicle control was directly injected into tissue of ganglion using the specific designed needle to confirm the functional intact of Vagus and the baseline BP. In the following observation, NPY, Pro34 (Y R agonist), and NPY13-36( $\mathrm{Y}_{2} \mathrm{R}$ agonist) were injected, respectively. The net changes in mean arterial pressure (MAP) were collected and analyzed by using the software of Labchart 7.

\section{Single-cell quantitative RT-PCR}

In order to test the target mRNA examination in afferent-specific manner, qRT-PCR was carried out with identical procedures as previously described [16] in single-neurons identified by standard validation [13].

\section{Neuron afferent type identification}

Afferent fiber types of isolated neurons were classified as myelinated A-, Ah-, and unmyelinated C-types according to electrophysiological and pharmacological validations [13] as well as morphological parameters [14]. The neurons from slice preparation were identified by afferent conduction velocity (CV) [45]. The afferent modality of baroreceptor of the 1st-order BRNs housed in nodose were also identified by the fluorescence [46].

\section{ACKNOWLEDGMENTS}

Contributors: These authors would like to thank Dr. Rong Huo, Dr. Xue-Lian Li, and Dr. Ning Wang for their helps and valuable inputs in RT-PCR techniques and data interpretations. These authors would also like to thank Dr. Zhenwei Pan for his final proofreading.

Funding: This work was supported by the NSFC grant 31171122 and 81573431 (to B.Y.L.) and 81173051 (to G.F.Q.).

\section{CONFLICTS OF INTEREST}

These authors declare no conflicts of interests.

\section{REFERENCES}

1. Zukowska-Grojec Z, Shen GH, Capraro PA, Vaz CA. Cardiovascular, neuropeptide $\mathrm{Y}$, and adrenergic responses in stress are sexually differentiated. Physiol Behav. 1991; 49:771-777.

2. Wocial B, Ignatowska-Switalska H, Pruszczyk P, Jedrusik P, Januszewicz A, Lapinski M, Januszewicz W, ZukowskaGrojec Z. Plasma neuropeptide Y and catecholamines in women and men with essential hypertension. Blood Press. 1995; 4:143-147.

3. Yang SN, Narvaez JA, Bjelke B, Agnati LF, Fuxe K. Microinjections of subpicomolar amounts of NPY(13-36) into the nucleus tractus solitarius of the rat counteract the vasodepressor responses of NPY(1-36) and of a NPY Y1 receptor agonist. Brain Res. 1993; 621:126-132. 
4. Diaz-Cabiale Z, Fuxe K, Covenas R, Gonzalez-Baron S, Narvaez JA. Angiotensin II modulates the cardiovascular responses to microinjection of NPY Y1 and NPY Y2 receptor agonists into the nucleus tractus solitarii of the rat. Brain Res. 2003; 983:193-200.

5. Narvaez JA, Aguirre JA, Fuxe K. Subpicomolar amounts of NPY(13-36) injected into the nucleus tractus solitarius of the rat counteract the cardiovascular responses to L-glutamate. Neurosci Lett. 1993;151:182-186.

6. Sato K, Crofton JT, Wang YX, Share L. Effects of gender on the central actions of neuropeptide $\mathrm{Y}$ and norepinephrine on vasopressin and blood pressure in the rat. Brain Res. 1995; 689:71-78.

7. Coelho EF, Ferrari MF, Maximino JR, Fior-Chadi DR. Change in the expression of NPY receptor subtypes Y1 and $\mathrm{Y} 2$ in central and peripheral neurons related to the control of blood pressure in rats following experimental hypertension. Neuropeptides. 2004; 38:77-82.

8. Wang L, Rao F, Zhang K, Mahata M, Rodriguez-Flores JL, Fung MM, Waalen J, Cockburn BA, Hamilton BA, Mahata SK, O'Connor DT. Neuropeptide Y(1) Receptor NPY1R discovery of naturally occurring human genetic variants governing gene expression in cella as well as pleiotropic effects on autonomic activity and blood pressure in vivo. $\mathrm{J}$ Am Coll Cardiol. 2009; 54:944-954.

9. Gradin KA, Buus CL, Li JY, Frobert O, Simonsen U. Neuropeptide Y2 receptors are involved in enhanced neurogenic vasoconstriction in spontaneously hypertensive rats. Bri J Pharmacol. 2006; 148:703-713.

10. Wei Z, Zhang K, Wen G, Balasubramanian K, Shih PA, Rao F, Friese RS, Miramontes-Gonzales JP, Schmid-Schoenhein GW, Kim HS, Mahata SK, O'Connor DT. Heredity and cardiometabolic risk: naturally occurring polymorphisms in the human neuropeptide $\mathrm{Y}(2)$ receptor promoter disrupt multiple transcriptional response motifs. J Hypertens. 2013; 31:123-133.

11. Han LM, Ban T, Liu Y, Yuan M, He JL, Wen X, Qiao Z, Qiao GF, Li BY. Hyperpolarization-activated currentmediated slow afterhyperpolarization in myelinated Ah-type of baroreceptor neurons isolated from adult female rats. Int J Cardiol. 2014; 172:e106-108.

12. Li BY, Qiao GF, Feng B, Zhao RB, Lu YJ, Schild JH. Electrophysiological and neuroanatomical evidence of sexual dimorphism in aortic baroreceptor and vagal afferents in rat. Am J Physiol Regul Integr Comp Physiol. 2008; 295:R1301-1310.

13. Li BY, Schild JH. Electrophysiological and pharmacological validation of vagal afferent fiber type of neurons enzymatically isolated from rat nodose ganglia. J Neurosci Methods. 2007; 164:75-85.

14. Lu XL, Xu WX, Yan ZY, Qian Z, Xu B, Liu Y, Han LM, Gao RC, Li JN, Yuan M, Zhao CB, Qiao GF, Li BY. Subtype identification in acutely dissociated rat nodose ganglion neurons based on morphologic parameters. Int J Biol Sci. 2013; 9:716-727.
15. Qiao GF, Li BY, Lu YJ, Fu YL, Schild JH. 17Beta-estradiol restores excitability of a sexually dimorphic subset of myelinated vagal afferents in ovariectomized rats. Am J Physiol Cell Physiol. 2009; 297:C654-664.

16. Qiao GF, Qian Z, Sun HL, Xu WX, Yan ZY, Liu Y, Zhou JY, Zhang HC, Wang LJ, Pan XD, Fu Y. Remodeling of hyperpolarization-activated current, Ih, in Ah-type visceral ganglion neurons following ovariectomy in adult rats. PLoS One. 2013; 8:e71184.

17. He JL, Li JN, Zuo CM, Wang LQ, Wen X, Zuo M, Guan J, Wu D, Song DX, Yu X, Qu MY, Liu Y, Qiao GF, et al. Potentiation of 17beta-estradiol on neuroexcitability by $\mathrm{HCN}$-mediated neuromodulation of fast-afterhyperpolarization and late-afterdepolarization in low-threshold and sex-specific myelinated Ah-type baroreceptor neurons via GPR30 in female rats. Int J Cardiol. 2015; 182:174-178.

18. Li JN, Qian Z, Xu WX, Xu B, Lu XL, Yan ZY, Han LM, Yuan M, Schild JH, Qiao GF, Li BY. Gender differences in histamine-induced depolarization and inward currents in vagal ganglion neurons in rats. Int J Biol Sci. 2013; 9:1079-1088.

19. Santa Cruz Chavez GC, Li BY, Glazebrook PA, Kunze DL, Schild JH. An afferent explanation for sexual dimorphism in the aortic baroreflex of rat. Am J Physiol Heart Circ Physiol. 2014; 307:H910-921.

20. Zhou YH, Sun LH, Liu ZH, Bu G, Pang XP, Sun SC, Qiao GF, Li BY, Schild JH. Functional impact of the hyperpolarization-activated current on the excitability of myelinated A-type vagal afferent neurons in the rat. Clin Exp Pharmacol Physiol. 2010; 37:852-861.

21. Calik MW, Radulovacki M, Carley DW. A method of nodose ganglia injection in Sprague-Dawley rat. J Visual Exp. 2014:e52233.

22. Li BY, Schild JH. Patch clamp electrophysiology in nodose ganglia of adult rat. J Neurosci Methods. 2002; 115:157-167.

23. Doan TN, Stephans K, Ramirez AN, Glazebrook PA, Andresen MC, Kunze DL. Differential distribution and function of hyperpolarization-activated channels in sensory neurons and mechanosensitive fibers. J Neurosci. 2004; 24:3335-3343.

24. Cheng PW, Wu AT, Lu PJ, Yang YC, Ho WY, Lin HC, Hsiao $\mathrm{M}$, Tseng CJ. Central hypotensive effects of neuropeptide $\mathrm{Y}$ are modulated by endothelial nitric oxide synthase after activation by ribosomal protein S6 kinase. Bri J Pharmacol. 2012; 167:1148-1160.

25. Andresen MC, Doyle MW, Bailey TW, Jin YH. Differentiation of autonomic reflex control begins with cellular mechanisms at the first synapse within the nucleus tractus solitarius. Braz J Med Biol Res. 2004; 37:549-558.

26. Diaz-Cabiale Z, Flores-Burgess A, Parrado C, Narvaez M, Millon C, Puigcerver A, Covenas R, Fuxe K, Narvaez JA. Galanin receptor/neuropeptide y receptor interactions in 
the central nervous system. Curr Protein Pept Sci. 2014; 15:666-672.

27. Burdyga G, de Lartigue G, Raybould HE, Morris R, Dimaline R, Varro A, Thompson DG, Dockray GJ. Cholecystokinin regulates expression of $\mathrm{Y} 2$ receptors in vagal afferent neurons serving the stomach. J Neurosci. 2008; 28:11583-11592.

28. Ekblad E, Edvinsson L, Wahlestedt C, Uddman R, Hakanson R, Sundler F. Neuropeptide Y co-exists and co-operates with noradrenaline in perivascular nerve fibers. Regul Pept. 1984; 8:225-235.

29. Myers AK, Farhat MY, Vaz CA, Keiser HR, ZukowskaGrojec Z. Release of immunoreactive-neuropeptide by rat platelets. Biochem Biophys Res Commun. 1988; 155:118-122.

30. Morris M, Kapoor V, Chalmers J. Plasma neuropeptide Y concentration is increased after hemorrhage in conscious rats: relative contributions of sympathetic nerves and the adrenal medulla. J Cardiovasc Pharmacol. 1987; 9:541-545.

31. Edvinsson L, Emson P, McCulloch J, Tatemoto K, Uddman R. Neuropeptide Y: cerebrovascular innervation and vasomotor effects in the cat. Neurosci Lett. 1983; 43:79-84.

32. Rudehill A, Sollevi A, Franco-Cereceda A, Lundberg JM. Neuropeptide Y (NPY) and the pig heart: release and coronary vasoconstrictor effects. Peptides. 1986; 7:821-826.

33. Liu Y, Zhou JY, Zhou YH, Wu D, He JL, Han LM, Liang XB, Wang LQ, Lu XL, Chen H, Qiao GF, Shou W, Li BY. Unique Expression of Angiotensin Type-2 Receptor in SexSpecific Distribution of Myelinated Ah-Type Baroreceptor Neuron Contributing to Sex-Dimorphic Neurocontrol of Circulation. Hypertension. 2016; 67:783-791.

34. Zukowska-Grojec Z, Dayao EK, Karwatowska-Prokopczuk E, Hauser GJ, Doods HN. Stress-induced mesenteric vasoconstriction in rats is mediated by neuropeptide Y Y1 receptors. Am J Physiol. 1996; 270:H796-800.

35. Lundberg JM, Modin A. Inhibition of sympathetic vasoconstriction in pigs in vivo by the neuropeptide Y-Y1 receptor antagonist BIBP 3226. Bri J Pharmacol. 1995; 116:2971-2982.

36. Callanan EY, Lee EW, Tilan JU, Winaver J, Haramati A, Mulroney SE, Zukowska Z. Renal and cardiac neuropeptide Y and NPY receptors in a rat model of congestive heart failure. Am J Physiol Renal Physiol. 2007; 293:F1811-1817.

37. Li JN, Li XL, He J, Wang JX, Zhao M, Liang XB, Zhao SY, Ma MN, Liu Y, Wang YB, Chen H, Qiao GF, Li BY.
Sex- and afferent-specific differences in histamine receptor expression in vagal afferents of rats: A potential mechanism for sexual dimorphism in prevalence and severity of asthma. Neuroscience. 2015; 303:166-177.

38. Huo R, Xu WX, Han LM, He JL, Liu Y, Lu XL, Liu SZ, Yuan M, Chen H, Yan JL, Qiao GF, Li BY. Fine tuning of calcium on membrane excitation of baroreceptor neurons in rats. Int J Cardiol. 2014; 174:883-887.

39. Li BY, Glazebrook P, Kunze DL, Schild JH. KCa1.1 channel contributes to cell excitability in unmyelinated but not myelinated rat vagal afferents. Am J Physiol Cell Physiol. 2011; 300:C1393-1403.

40. Xu WX, Ban T, Wang LQ, Zhao M, Yin L, Li G, Chen H, Schield J, Qiao GF, Yan JL, Li BY. KCa1.1 beta4subunits are not responsible for iberiotoxin-resistance in baroreceptor neurons in adult male rats. Int J Cardiol. 2015; 178:184-187.

41. Li BY, Feng B, Tsu HY, Schild JH. Unmyelinated visceral afferents exhibit frequency dependent action potential broadening while myelinated visceral afferents do not. Neurosci Lett. 2007; 421:62-66.

42. Fan W, Andresen MC. Differential frequency-dependent reflex integration of myelinated and nonmyelinated rat aortic baroreceptors. Am J Physiol. 1998; 275:H632-640.

43. Fan W, Schild JH, Andresen MC. Graded and dynamic reflex summation of myelinated and unmyelinated rat aortic baroreceptors. Am J Physiol. 1999; 277:R748-756.

44. Anish TS, Shahulhameed S, Vijayakumar K, Joy TM, Sreelakshmi PR, Kuriakose A. Gender Difference in Blood pressure, Blood Sugar, and Cholesterol in Young Adults with Comparable Routine Physical Exertion. J family Med Prim Care. 2013; 2:200-203.

45. Wang LQ, Liu SZ, Wen X, Wu D, Yin L, Fan Y, Wang Y, Chen WR, Chen P, Liu Y, Lu XL, Sun HL, Shou W, et al. Ketamine-mediated afferent-specific presynaptic transmission blocks in low-threshold and sex-specific subpopulation of myelinated Ah-type baroreceptor neurons of rats. Oncotarget. 2015; 6:44108-441122. doi: 10.18632/ oncotarget.6586.

46. Zhang YY, Yan ZY, Qu MY, Guo XJ, Li G, Lu XL, Liu Y, Ban T, Sun HL, Qiao GF, Li BY. KCa1.1 is potential marker for distinguishing Ah-type baroreceptor neurons in NTS and contributes to sex-specific presynaptic neurotransmission in baroreflex afferent pathway. Neurosci Lett. 2015; 604:1-6. 